\title{
SHOULD ASCARIASIS BE CONSIDERED AS A REPRODUCTOLOGY PROBLEM?
}

DOI: 10.36740/WLek202109120

\author{
Valentyna Sklyarova, Kateryna Shatylovich, Pavlo Sklyarov, Anzhelika Filipyuk \\ DANYLO HALYTSKYY LVIV STATE MEDICAL UNIVERSITY, LVIV , UKRAINE
}

\begin{abstract}
The aim: To study the epidemiological situation of ascariasis among women with pathology of the reproductive system on the basis of a literature database (PubMed, Medline, Google Scholar, PLOS, Hindawi) and to present our experience with ascariasis and pathology of reproductive system.

Materials and methods: We investigated parasitic invasions in 174 women reproductive losses and 186 patients with primary infertility.

Results: The results performed in women with infertility and reproductive losses have proved the role of parasitic infection in the emergence of disorders of hormonal homeostasis, endothelial-lymphocytic dysfunction, severe vaginal and intestinal dysbiosis and, as a consequence, reproduction of conditionally pathogenic flora, etiopathogenetic risk factors for the development of various forms of women's reproductive health pathology.

Conclusions: More global attention to the diagnosis and treatment of parasitic infections in the examination of women with infertility and reproductive losses is warranted. The influence of ascariasis as a source of autoinfection of the gastrointestinal tract, allowed us to consider the presence of this invasion a risk factor for the development of chronic inflammatory process of the lower genital tract.
\end{abstract}

KEY WORDS: ascariasis, infertility, habitual miscarriage

Wiad Lek. 2021;74(9 p.l):2138-2146

\section{INTRODUCTION}

Preserving the reproductive health of women and the birth of healthy children are one of the priority tasks of national security of each state, especially Ukraine during the period of internal and external migration, anti-terrorist operation, COVID-19 infection. Important indicators of the reproductive health status of the female population include the percentage of infertility and habitual miscarriage. According to V.V. Kaminsky, OM Yuzko, F.V. Dakhno, V.D. Zukina, the incidence of infertility and pregnancy loss in Ukraine were between 10 and $20 \%$. The effectiveness of infertility treatment in the application of modern methods of diagnostics and use of leading technologies (IVF and ICSI) in gynecological practice is up to $50 \%$. When examining women with reproductive losses, there is a problem of establishing the cause of miscarriages, dead pregnancies, perinatal losses, ectopic pregnancy. Particularly difficult to treat are chronic inflammatory diseases of the pelvic organs and lower urinary tract, chronic endometritis, peritoneal infertility. The impact of worm infestations on the reproductive function of women often overlooked by physicians, especially gynecologists [1].

The problem of helminthiasis in obstetric and gynecological practice poorly understood. Helminths detect in 30\% of women who seek medical attention for gynecological disorders: recurrent cervicitis, vaginitis and vulvitis of different etiology $[2,3]$.

Ascariasis manifests a variety of clinical symptoms with lesions of the liver, gall bladder, pancreas, lungs [4-7]. The presence of ascaris in a woman's body may be one of the factors in the development of tubal, tubal-peritoneal and endocrine infertility, taking into account the toxic effects of the products of ascarid on the thyroid gland, ovaries and adrenal glands.

\section{THE AIM}

The aim of our work was to study the epidemiological situation of ascariasis among women with pathology of the reproductive system on the basis of a literature database (PubMed, Medline, Google Scholar, PLoS, Hindawi). We also present our clinical case and observations.

\section{MATERIALS AND METHODS}

In the first stage, we studied the clinical and epidemiological problem of the impact of ascariasis on the reproductive system in the world in recent years based on literature data (PubMed, Medline, Google Scholar, PLoS, Hindawi).

In parallel, we examined women with pathology of the reproductive system at the Lviv City Family Planning Center, west part of Ukraine. 360 women were surveyed to achieve their goals and objectives. The surveyed patients were divided into groups according to the research objectives, of which 174 patients (1st group) who addressed the purpose of the examination in the planning of pregnancy with recurrent pregnancy loss (RPL) (N96); Group II - 
186 women with primary infertility (PI) within 1-20 years (Z31,6, N97, excluded N 97.4). The control group included 160 women between the ages of 18 and 40 with one or two children without reproductive losses, no obstetric and gynecological and somatic anamnesis (refer for the purpose of prophylactic examination, who was advised to have an uterine cavity pipeline before IUD), Z30).

At the stage of pregravid examination in patients of group I in the analysis of anamnestic anamnesis, the condition, clinical course of previous pregnancies, childbirth, postpartum period and condition of newborns were further studied; frequency and structure of reproductive losses are determined. In women of group II, the duration of infertility, the nature of previous treatment and diagnostic procedures, the number of assisted reproductive technologies in history were taken into account. In the presence of extragenital pathology, consultations were carried out by a dermatologist, gastroenterologist, endocrinologist, nephrologist, mammologist, and together with specialists, a plan of subsequent treatment was worked out.

By the stage of inclusion in this survey, all patients were examined for infectious agents of the reproductive system and research according to clinical protocols before surgery, patients of I and II groups for hormonal parameters, the presence of parasites.

Diagnosis of chlamydia, trichomoniasis, herpes I and II types, bacquinosis and CMV was performed by PCR. The diagnosis of genital mycoplasmosis, ureaplasmosis was made when the pathogen was detected in the amount of $10^{4} \mathrm{CFU} / \mathrm{ml}$ or more. Genital candidiasis was diagnosed in the presence of clinical manifestations and in the case of detection of colonies of fungi in the amount of $10^{4} \mathrm{CFU} /$ $\mathrm{ml}$ or more (Sinevo, Esculab).

The levels of thyrotropic, luteinizing and folliclestimulating hormones, free and total testosterone, cortisol, estradiol, insulin were determined in the blood plasma; the presence of antibodies to thyroid peroxidase and antibodies to thyroglobulin; titers of IgG immunoglobulins to ascarides, lamblia, toxocar, TORCH pathogens (Sinevo, Esculab).

In case of detection of vaginal and intestinal microbiocenosis disorders, presence of infectious agents of the reproductive system or hormonal or parasitic pathologies, correction of the detected changes was carried out before inclusion in this study. Exclusion criteria were: age less than 18 years and over 40 years, hormonal medication at the time of the study, malignancies in the anamnesis, body mass index over 30 , external genital endometriosis, corticosteroid therapy, antiphospholipid syndrome. All patients who participated in the study signed a voluntary informed consent.

The activity of NO synthases in lymphocyte lysates was determined according to the method of VV Sumbayev. Studies on the activity of arginase were performed according to the method of Geyer J.W., Dabich D. The concentration of stable metabolite NO-2 as active $\mathrm{NO}$ was determined using Gris reagent in blood plasma and lymphocyte lysate (dilution 1:10). Studies of L-arginine content in blood plasma and lymphocyte lysate were performed by the method of Aleynikov TL.

For the determination of antibodies to parasites (Toxocara canis, Giardia Lamblia and Ascaris lumbricoides), kits of Vitrotest Anti (Ramintech, Ukraine) were used.

Parasitological examination included coproscopy and enterobiasis examination. Each stool sample was developed using the methods of Kato, Füleborn, and Schulman. Enterobiosis examination was performed using the adhesive tape method (according to Graham) and the method of perianal scraping (according to Torgushin).

Statistical processing of results was performed using SPSS 7.0 and Microsoft Excel 2000 [8].

A literature review was conducted.

\section{RESULTS}

\section{STATISTICS AND EPIDEMIOLOGY - THE REALITIES OF UKRAINE}

The problem of official statistics and the real situation of detection of parasites in the population exists from the standards of providing medical care of the USSR. All cases of worm infestation had to be reported to the health service, which carried out a number of paper and organizational work, and the main discomfort for the individual, or the family, where ascariasis or enterobiasis was found. Therefore, hiding detected invasions, presenting fictitious certificates and survey results to childcare facilities or schools, advocacy for self-medication, over-the-counter selling of medicines, mass advertising of medicines, and promoting the profession of doctor in the media, contributes to the spread of not only parasitic lesions, but also disease and mortality $[9,10]$. In addition to the above factors, the awareness of obstetricians and gynecologists about diseases and pathological conditions caused by worms is insufficient not only in Ukraine but also in the countries of the European Union and the United States of America [11].

According to official statistics, up to 500,000 parasitic infections are detected annually in Ukraine. However, the real scale of the spread of parasitic invasions in Ukraine is much larger and, given different expert estimates, the number of infected can reach 5millions. In our country, the incidence of helminthiasis is 1333 per 100 thousand population. The dynamics of registering helminthiasis cases in Ukraine does not correlate with the number of sales of anthelmintic preparations: against the background of a decrease in the incidence of helminthiasis per year $(320,614$ cases in 2005 and 243,164 in 2009), there is an annual increase in the sale of helminths (from 41,65,500 packages in 2005 to 5895492 in 2009). This situation is largely due to the fact that the majority of helminthoses are recorded, which are the reason for hospitalization in the hospital, while the helminthiasis found in private clinics and other "remedies" remain unaddressed. Considering that one to three packages of anthelmintic drug are required for one course of treatment, the real prevalence of helminthiasis in Ukraine annually is more than 3 million cases [12]. 
The dynamics of incidence of ascariasis in Russia among the adult population has shown that since 2003, there has been an increase in the incidence. The highest rates were recorded in 2003, 2004, 2005, 2006, 2007 and amounted to $34.70 ; 97.40 ; 108.20 ; 161.70 ; 63.7$ per 100 thousand population respectively. Most often women have helminth disease - in $57.97 \%$ of cases. Epidemiological analysis of ascariasis disease by factors and risk groups of the Karaganda region has revealed that adults aged 21-44 years are at risk, with a rate of $78.7 \%$ of cases. [13].

There are more than 10 manufacturers of anti-theft drugs in the pharmaceutical market of Ukraine: Aldazol (KVZ, Ukraine), Angelmeks (Agropharm, Ukraine), Vormil (Windlas Helsker Pvt. Ltd. for Milli Helsker Ltd., India / UK), Zentel (Pharmacler for GlaxoSmikl Exports Ltd., France / United Kingdom), Nemozol (Ipka Laboratories Ltd., India), Pharmox (Farm Factory, Ukraine), Agelmin-Darnica (Darnitsa, Ukraine), Vermox (Gideon Richter, Romania / Hungary), Vermox (Janssen- Silage SPA / Johnson \& Johnson, Italy / Russian Federation), Mebendazole (Grundex, Latvia), Decaris (Gideon Richter, Romania / Hungary), Levamisole (Elegant India, India), Levamisole-Health (Health Ukraine), Helmintox (Inota Shuzi for Lab. Innotek International, France), Nemocide (Ipka Laboratories Ltd., India), Pirantel (Pharm. Factory, Ukraine), Pirantel Polpharma (Medana Pharma AO, Poland), while the anti-parasitic agents Albel (Kusum Farm, Ukraine) are being introduced to the market [tabletki.ua]. In addition to official medicine, drugstore shelves, online warehouses, prom.ua and olx ads filled with a variety of biologically active anthelminthic supplements that treat everything from psoriasis to infertility and oncology: Inotoxic, Anti-Crimea, Degelmine, Biola, Phytophthit, Phytolithic Ternate, Black Walnut, Antivorm, Strogelmint, etc. etc. Network marketing companies such as Coral Club, Neways, Choice, Amway, NSP, Vision, etc. they start their own medical and preventative work with potential clients with anti-theft program, cleansing and detoxification supplements. Considering the presence on the market of both pharmacy anthelmintics, and the variety of supplements and herbal remedies, it is possible to state the significant needs of medicines of anti-parasitic influence among the population, the high market of sales and significantly reduced official statistics.

\section{ASCARIASIS - MORPHOLOGY, CYCLE OF DEVELOPMENT, DIAGNOSTIC POSSIBILITIES}

Ascaris are two-horned large spindle-shaped worms with elongated, non-segmented cylindrical body length of 15-40 $\mathrm{cm}$. The adult has a cylindrical body, pointed at the ends, yellow-pink in color and capable of laying about 240,000 eggs in 24 hours, 64 million during the year. The mouth is surrounded by three lips (one dorsal and two ventral), on which there are a pair of sensitive papillae (Fig. 1). [14].

Eggs can be fertilized and unfertilized. Unfertilized eggs are oval or irregular in shape, large ( 80 x 55 microns) (Fig. 2 ). Protein shell uneven, yellow-brown in color, it may not be at all. The entire egg cavity is filled with yolk cells [15].

Fertilized eggs (Fig. 3) rounded or oval, 60-70 x 40-50 $\mu \mathrm{m}$ in size, yellow-brown in color. The outer protein shell is hunchbacked, the inner - thick, smooth, colorless. Inside the egg is a round germ cell of dark color, between it and the shell of the egg at the poles of free space. The protein shell may be absent, then the eggs have a smooth surface, colorless or light yellow. This is clearly seen in the examination of feces on worm eggs, as well as in the evaluation of urine sediment.

Most often, ascaris localized in the body in the small intestine. In the presence of both males and females, fertilized eggs are actively isolated, capable of continuing the biological cycle up to the stage of the larva, ready for infection. In order for the ascarid eggs to ripen in the soil, its humidity must be at least $4-8 \%$, and the temperature $+13-36^{\circ} \mathrm{C}$. The embryo develops, successively passing through the stages of the cell, morula (cluster of cells), gastrula, then the buds and at the end of the development process - the larvae. If the infection is of a non-intensive nature (there are 1-2 females of human ascaris in the human body), only unfertilized eggs are isolated, the detection of which allows to clarify the clinical picture of ascariasis [15].

The ascarids secrete a large number of eggs that, with the host's faeces, fall outside. From the soil, eggs can get into vegetables, vegetables, berries and fruits. Together with dust on shoes, wool of pets, with vegetable products, through the skin of hands, eggs can get ascarid on dishes, in drinking water and on food. When swallowed mature eggs, ascaris, which have passed the period of maturation in the ground, comes human infection. Given the popularity and frequency of the natural markets, ascariasis infection can occur during the trade and transportation of products. Eggs may be cockroaches and flies. During the migration of larvae, the ascaris from the liver to the heart and lungs, the larvae are able to move not only with the blood flow, but at any moment ready to "pass" through the wall of the vessel and get into one or another organ, causing destructive changes.

When the eggs of ascarids enter the human intestine, their shells are destroyed, releasing the larvae. Then the larvae begin a difficult migration path[16-20]:

- penetrate into the intestinal mucosa and further into the intestinal wall capillaries filled with blood;

- a large (portal) vein carrying blood from the intestine to the liver enters the liver;

- the inferior vena cava blood flow into the right side of the heart;

- reach the lungs with the help of the pulmonary artery;

- tearing the walls of the capillary vessels, enter the alveolar space and move through the bronchi and trachea with the help of eyelashes of the epithelial tissue (ciliated epithelium);

- reach the pharynx and oral cavity, where they swallow and again go into the stomach and then - into the intestine.

It is at the secondary entry into the intestines that adult larvae develop from the larvae (Fig. 4). 

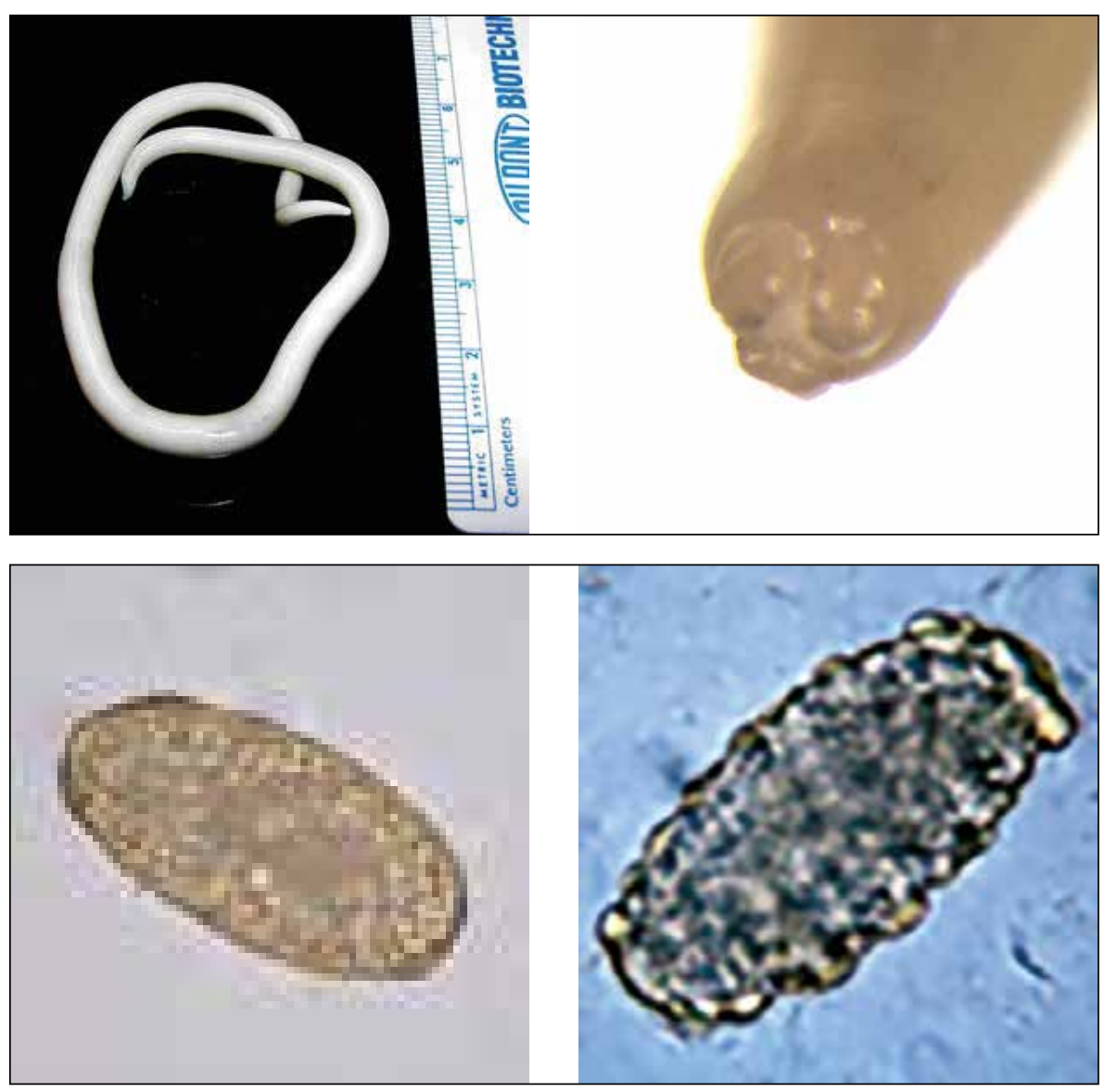

Fig. 1. Close up front end of adult A. lumbricoides.

Fig. 2. Ascaris lumbricoides unfertilized eggs.

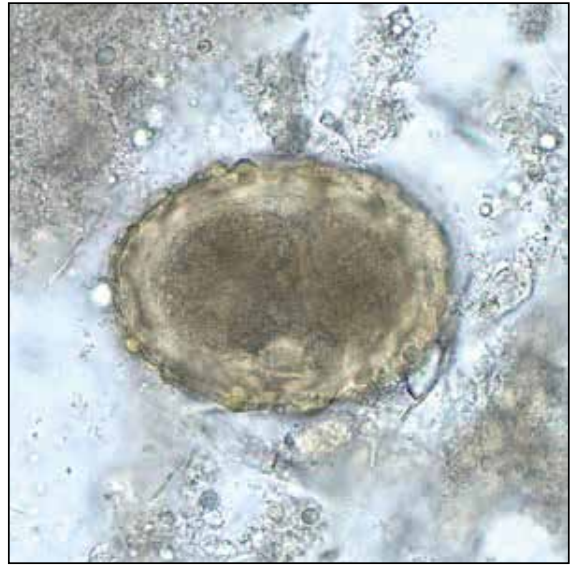

Fig. 3. Fertilized egg of A. lumbricoides in unpainted moist feces, with embryos at an early stage of development, 200x magnification. Lumbricoides without shell, fertilized egg in moist feces, 200x magnification.

The migration period of the larvae lasts 12-14 days. Migration is a prerequisite for the larvae to develop pubescent ascaris, capable of secreting eggs. In excrement eggs ascarid appear two and a half months after the time of invasion. Ascaris are capable of parasitizing the adult intestine for no more than 12 months.

The diagnostic possibilities of ascariasis are primarily based on the clinical manifestations and capabilities of laboratory diagnostics. However, given the different stages of persistence in the human body, the clinical symptoms and results of laboratory tests will have certain characteristics. Classically, ascariasis is characterized by the following main symptoms: frequent attacks of abdominal pain, which suddenly appear and pass; pallor or sometimes jaundice of the skin; body weight is not always below the age limit, with toxic effects on the thyroid gland and the development of autoimmune thyroiditis, overweight is observed; aversion to food or vice versa insatiability; nausea, especially evening, vomiting, increased salivation; chronic constipation or stool; poor sleep, gnashing of teeth in sleep; frequent colds and intestinal infections; psycho-emotional disorders [16-20].

At the initial hit, depending on the state of gastric acidity, the immune response of the gastrointestinal tract, the reaction of the organism can be manifested by cleansing from worms with clinical manifestations of food poisoning: nausea, diarrhea, impaired gas formation, moderate fever, mild fever with proper diet. In fecal examinations, worm eggs can detect occasionally unfertilized ascarid eggs, as the shell and parasites are destroyed, and the overall blood count has no specific changes.

In cases of violation of the local mechanisms of protection of acid, enzymatic and immune regulation of the digestive system, the entire development of ascariasis with the appropriate stages occurs. Thus, clinically, with the persistence of larvae of ascarid in the intestine and penetration into the mucous wall, abdominal pain is observed, especially in the right iliac and tympanic regions, nausea, decreased appetite, impaired bowel movement and gas formation, weakness. In laboratory examinations 


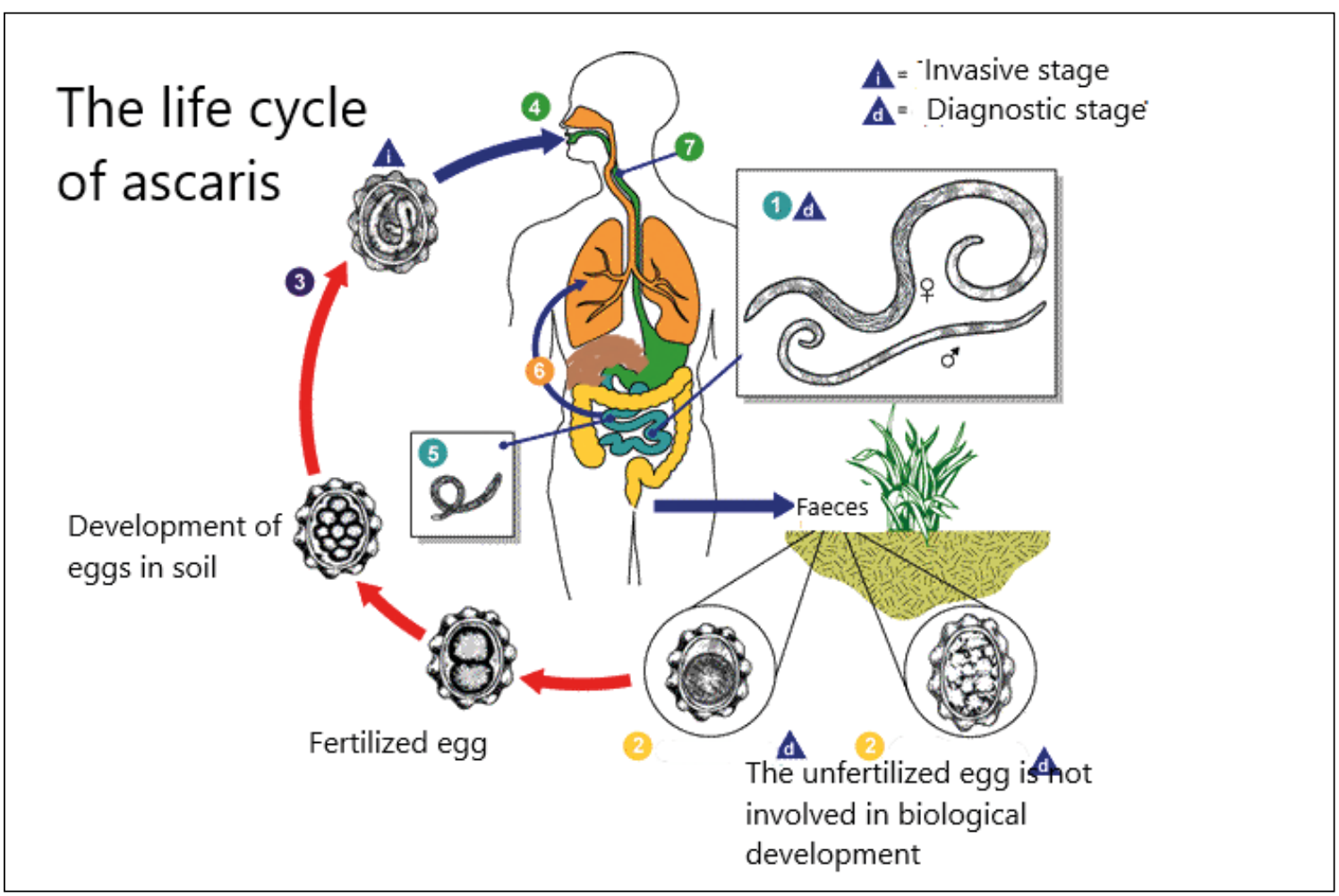

Fig. 4. The life cycle of ascaris

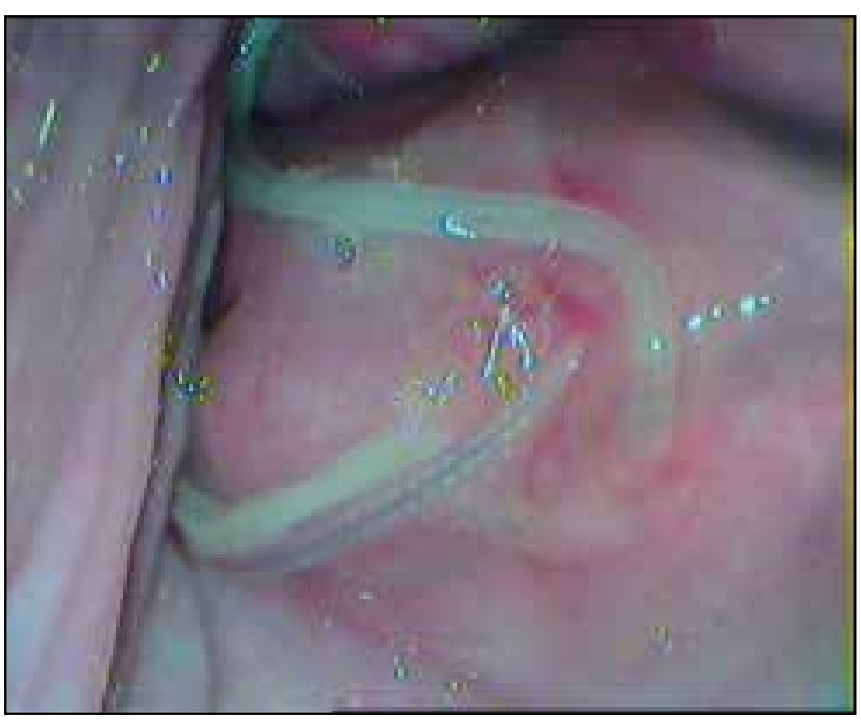

Fig. 5. Presence of ascaris in the vagina for 30 days in patients with complicated postpartum period.

reveal unfertilized eggs of ascaris, in the examination of the general blood test up to $20 \%$ observe a slight increase in ESR and the number of rod-core leukocytes.

In the pulmonary stage of development, the main symptoms are attributed to clinical signs of chronic bronchitis, in some cases with re-invasions with an allergic component. Since the education of a wide range of physicians, as well as the population, evaluates worms as intestinal invasion, the study of sputum for the detection of eggs or larvae of ascaris is not clinically necessary. Symptoms of pulmonary lesions are estimated as manifestations of SARS, which promotes the progression and re-ingestion of larvae.

Symptoms and complications of ascariasis directly depend on the number of sexually mature persons parasitizing in the human body. Chronic pain in various parts of the abdomen, intestinal dysbiosis, scleral and skin jaundice, anemia, chronic fatigue syndrome, allergic bronchitis and other allergic statuses, recurrent respiratory diseases, and hypersensitivity are manifestations of life activities of various species. When examining the feces reveal fertilized eggs ascarid, 50\% find that in the assessment of the total blood count can be noted moderate anemia and lymphocytosis. Eosinophilia, which doctors are accustomed to, is up to $15 \%$.

In the case of numerical invasion, the ascaris enter the stomach and can emit vomiting. They can crawl into the airways, penetrate the gall bladder and liver, causing obstruction, perforation, inflammatory processes down to septic conditions. Thus, live ascarids were detected in the bladder in patients with pain during catheterization of the bladder and were present in the urinary tract [21].

Diagnosis of ascaridosis: [22-24].

Laboratory:

- detection of ascarid eggs in the stool, urine sediment, smear of vaginal discharge, sputum;

- presence of eosinophilia, anemia, lymphocytosis, thrombocytosis in general advanced blood test. The presence of more than two items should alert you to ascaridosis.

- increased titer of Ig antibodies to ascarid

- moderate growth of bilirubin, ALT, AST, THG

Ultrasonic: the presence of movement of ascaris in the gallbladder, intestine, in abscess of the liver.

MRI: detection on sections of the parasite. 


\section{EFFECTS OF ASCARIDOSIS ON WOMEN'S REPRODUCTIVE HEALTH}

There is no study of the effects of ascaridosis on a woman's reproductive function mass. In the domestic and foreign literature, there is a greater frequency of work on the impact of earthworm infestations on pregnancy, postpartum and the condition of newborns.

A survey of 174 women with reproductive losses on parasitic invasions revealed eggs of ascarid in $29.3 \%$ $\left(\chi^{2}=20, p<0.05\right)$ (at the same time - positive titers of IgG to ascarid - in $11.5 \%\left(\chi^{2}=6.21, \mathrm{p}=0.012\right)$. Detection of ascaridosis by combined methods: Fecal examination of worm eggs and determination of IgG for ascarid showed a positive result in 89 women from 186 primary infertility examinations (47.9\%): fertilized and unfertilized ascarid eggs in feces were identified in 26 of 186 women 14.0\%) $\left(\chi^{2}=4.69, p=0.03\right)-3$ times higher than in the control group, positive $\mathrm{IgG}$ levels for ascarids were observed in 75 of 186 women $(40.3 \%)\left(\chi^{2}=42,5, p<0.05\right)-26$ times higher than the group control.

Patients with ascariasis showed characteristic abdominal palpation pain in the tympanic and right iliac regions; chronic subfebrile disease $\left(37-37.4^{\circ} \mathrm{C}\right)$ occurred in $21.6 \%$ of cases with this nosology. As a result of a comprehensive blood count in patients with ascariasis, eosinophilia was observed in $13.7 \%$ of women, platelet count increased from $350-480$ by 109 / 1 in $19.6 \%$, which was not detected in any patient with toxocariasis, enterobiasis. and in women without worm infestation, which coincides with the results of colleagues [25]. Lymphocytosis (40-55\%) in the blood was a characteristic symptom in 29 patients with toxocarosis and ascariasis.

In patients with parasitic lesions and reproductive losses compared with patients without worm infestation found: Gardnerella vaginalis -3 times more $(\mathrm{CI}=2,1-12,3, \chi 2=$ $8,7, \mathrm{p}<0,01, \mathrm{r}=0,22)$; pathogenic growth of Esherichia coli -2.7 times $\left(\mathrm{CI}=1.4-1.7, \chi^{2}=5.5, \mathrm{p}=0.02, \mathrm{r}=0.18\right)$; Ureaplasma urealyticum and parvum -1.7 times $(\mathrm{CI}=$ 11.6-27, $\chi^{2}=5.2, p=0.02, r=0.18$ ); groups of non-specific inflammatory infectious agents: Proteus $s p$, Klebsiella sp, S. aureus, S. Agalactiae - 2.9-fold (CI = 2.1-12.3, $\chi^{2}=$ $7.8, \mathrm{p}<0.01, \mathrm{r}=0,21)$ against the background of dysbiotic changes in the intestine: growth of 1,9 times Esherichia coli with hemolytic properties $\left(\mathrm{CI}=10,5-25,2, \chi^{2}=6,8\right.$, $\mathrm{p}<0,01, \mathrm{r}=0,2)$, the reproduction of fungi of the genus Candida 3.4 times $\left(\mathrm{CI}=0.7-9.3, \chi^{2}=7.4, \mathrm{p}<0.01, \mathrm{r}=\right.$ 0.21 ) and a deficit of 1.7 times adequate level lactobacilli $\left(\mathrm{DI}=10.5-25.5, \chi^{2}=5, \mathrm{p}=0.026, \mathrm{r}=0.17\right.$ ) [Sklyarova VA 2014]. Against the background of parasitic lesions in women with Ureaplasma urealyticum infertility, parvum was found in $51.8 \%$ of cases $(\mathrm{p}<0.05)$, bacterial vaginosis in $31.5 \%(\mathrm{HV}=7.7 ; 95 \% \mathrm{CI} 3.5-16.9)$, which was 5.5 times higher than those of the control group $(5.6 \%)(p<0.01)$. Signs of pronounced vaginal dysbiosis were observed in $54.6 \%$ of the surveyed women with ascariasis and in $26.9 \%$ of patients without $\mathrm{PU}(\mathrm{p}<0.05)$, which makes it possible to ascertain the aggressive effect of parasitic invasion on vaginal microbiocenosis [26].
Analysis of anamnesis and clinical manifestations in women with ascaridosis revealed the presence of breast pathology in $43.9 \%$ of cases $(\chi 2=20.2 ; \mathrm{p}<0.01$; $\mathrm{CI}=34.3$ $53.7, \mathrm{r}=0.28)$, of the gastrointestinal tract $-40.7 \%(\chi 2=36$, $\mathrm{p}<0.01 ; \mathrm{CI}=31.1-50.3, \mathrm{r}=0.38)$, acne $-14.3 \%\left(\chi^{2}=7,7\right.$, $\mathrm{p}<0.01 ; \mathrm{CI}=7.4-21.2, \mathrm{r}=0.18)$, urinary tract pathology in $20.9 \%\left(\chi^{2}=13.7, \mathrm{p}<0.01 ; \mathrm{CI}=12,9-28,9, \mathrm{r}=0,23\right)$, thyroid - in $16,5 \%(\chi 2=6,9, \mathrm{p}<0,01 ; \mathrm{CI}=9,2-23,8, \mathrm{r}=$ 0,17 ) cases that substantiate the feasibility of screening for worms in women with these diseases.

Pathological changes of a thyroid gland at complex ultrasound and hormonal examination revealed $16.7 \%$ of those examined with ascariasis, which is 3 times more often than in the control $\left(\chi^{2}=3.76 ; \mathrm{p}<0.01 ; \mathrm{HV}=3.8 ; 95 \% \mathrm{CI}\right.$ 1.6-9.1), and 1.4 times compared with patients without worm infestation $(\mathrm{p}<0.05)$. Thyroid hormone levels were almost the same in women with and without worm infestation: TSH concentration was $1.75 \pm 0.2 \mathrm{mIU} / \mathrm{l}$ and $1.63 \pm$ $0.16 \mathrm{mIU} / \mathrm{l}$, respectively. The latter makes it possible to state the possibility of aggressive pathological influence of ascarid lesions on the function of the thyroid gland with the following negative consequences for the reproductive function of the woman [27].

It should be noted that complaints of recurrent cystitis and postponed history of pyelonephritis was observed by $26.4 \%$ of women with detected parasite eggs in feces, compared with women without helminths (6.02\%). In 23.6\% of patients with helminthiasis, pinworm eggs and ascaris were found in the general urine test, in $34.7 \%$ of women with these pathologies' inflammatory changes in the urine and / or bacteriuria were detected.

Analysis of the evaluation of the immune response in the body of a woman on the background of persistence parasites showed a 2.1-fold increase in the proinflammatory cytokine content of IL- $1 \beta(\mathrm{p}<0.05)$; the anti-inflammatory IL-4 increased 2.7 -fold $(\mathrm{p}<0.05)$, the content of IFN- $\gamma$ increased $(61.0 \pm 0.17) \%(\mathrm{p}<0.05)$. In women with ascariasis in the blood plasma increased nitrite anion content up to $26.8 \pm 0.55 \mu \mathrm{mol} / \mathrm{l}(\mathrm{p}<0.05)$ and a decrease in the concentration of L-arginine to $61.2 \pm 5.2 \mu \mathrm{g} / \mathrm{ml}(\mathrm{g}<0.05)$ against the background of significant increase in nitrite anion content and iNOS activity $(\mathrm{p}<0.05)$ and decrease in eNOS activity $(\mathrm{p}<0.05)$ and L-arginine content in lymphocyte lysates [28].

In addition, it was found that in the primary infertility against the background of parasitic in $23.1 \%$ of cases, there was insufficiency of the luteal phase with relative hyperostrogeny and clinical signs of abnormal uterine bleeding ( $\mathrm{p}<0.01, \mathrm{HV}=9.9 ; 95 \% \mathrm{CI}=2.2-45.1)$. When ascaridosis was detected in women with primary infertility, elevated cortisol levels were observed in $26.8 \%$ of the women surveyed and, on average, amounted to $397.1 \pm 15.8 \mathrm{nmol} / \mathrm{l}$, which was $16 \%$ higher $(\mathrm{p}<0.01)$. than in control [29].

The results performed in women with infertility and reproductive losses have proved the role of parasitic infection in the emergence of disorders of hormonal homeostasis, endothelial-lymphocytic dysfunction, severe vaginal and intestinal dysbiosis and, as a consequence, reproduction 
of conditionally pathogenic flora, etiopathogenetic risk factors for the development of various forms of women's reproductive health pathology.

\section{DISCUSSION}

The impact of ascaridosis during pregnancy, initially or secondarily, leads to a disturbance in the system of the mother - placenta - fetus. This is due not only to chronic intoxication and immune disorders, but also to the development of anemia, a violation of the absorption of nutrients in the gastrointestinal tract. According to various authors, the incidence of ascariasis during pregnancy varies greatly. Since trophoblast initiates embryo implantation through the uterine wall during pregnancy, maternal immune mechanisms normally limit the aggressive effect on the rejection of decidual tissue without disturbing pregnancy. Simple parasites, nematodes, and cestodes can pass trans chorally and transplacentally and result in termination of pregnancy [30]. The most life-threatening pregnancy, pregnancy and fetal status include the following complications of ascaridosis [31-36]: Intestinal obstruction; perforative peritonitis; acute pancreatitis; acute appendicitis; liver abscesses; acute cholecystitis and inflammation of the bile ducts; shortness of breath on penetration of ascarid into the respiratory tract; purulent pleurisy, pneumonia. Symptoms of acute abdomen, pancreatitis, cholecystitis, intestinal obstruction, appendicitis are threatening for the development of peritonitis, septic condition, which are especially dangerous for the life of a pregnant woman and the subsequent development of the fetus. Premature rupture and effusion of amniotic fluid, most often causing perinatal morbidity or mortality, amid the inflammatory process. Given that the effects of progesterone have a weakening effect on the motility of the sphincter of Oddi during pregnancy, ascariasis in the biliary tract is most often seen in the third trimester.

The septic state is especially difficult after pregnancy termination against the background of ascariasis [37]. Cases of still pregnancies, involuntary miscarriages and pathologies of newborn children have been described [38]. Particularly noteworthy are cases of severe, drug-resistant toxicosis AND trimester of pregnant women in the period after 12 weeks. Thus, Ascaris lumbricoides may be the cause of continuous vomiting in a 13-week pregnant woman [39].

Pregnancy against parasitic diseases can be impaired at maternal, embryonic and placental levels [40]. Ascarid invasion can cause acute abdominal syndrome in pregnant women and the postpartum period [41]. In women with ascariasis, there is a direct correlation between the intensity of the invasion and the blood loss in childbirth [42]. This is due not only to the effect of helminths on the blood coagulation system by altering the enzymatic function of the liver, but also to chronic stress for the body [22, 31]. Toxic products of ascarid life cause anemia and impede blood coagulation. The coagulopathic properties of ascarid (increased clotting and increased thromboplastin time) may play a role in the occurrence of postpartum hemor- rhage $[43,44]$. Blood loss in the early postpartum period in patients with ascarid invasion was observed by different authors from 15-25\%. The results of their own clinical detection of ascaris in the vagina of the patient at 30 days postpartum are presented in Fig. 5. The postpartum period ran with a constant temperature reaction up to 37.4-37.8 ${ }^{\circ} \mathrm{C}$, against the background of antibacterials of different groups and blood significant secretions. Twice during the month there was an increase in temperature to $38.5-39.4^{\circ} \mathrm{C}$, during which the vacuum of aspiration of the contents of the uterine cavity was performed twice [45].

Ascarid eggs transplant and transplant the fetal immune response $[46,47]$. The papers describe the growth in the umbilical cord blood of newborns from ascarid-infected mothers of proinflammatory cytokines - IFN- $\gamma$ and IL-4-expressing CD4 + T cells compared with uninfected ascariasis. These data show pre-natal sensitization to A. lumbricoides, the fetal immune response [16]. Infants from infected mothers had higher levels of IL-10 plasma than those of uninfected mothers [24]. Chronic intoxication and immunodeficiency during pregnancy contributes to increased perinatal morbidity and allergy in children, leading to psychological exhaustion of women. Children from ascarid-affected mothers are born with a smaller fetal mass [15] and are at greater risk of contracting worm infections compared with children from uninfected mothers $[5,8]$.

In examining the literature on ascariasis, it should be noted that during the examination of heifers, buffalo infected with ascariasis noted the following changes: macrocytic hypochromic anemia, a moderate decrease in the level of neutrophils and lymphocytes, eosinophilia. On the antioxidant side, there was a marked increase in MDA and NO, combined with a decrease in CAT, SOD, GSH, and TAA levels [13].

The effect of ascarid on the development of deep vein thrombosis and pulmonary thromboembolism has been described [3]. The literature presents the findings of pulmonary embolism caused by thrombotic material, which, as a result of pathological anatomical examination revealed Ascaris lumbricoides and Candida albicans [40]; the presence of Ascaris lumbricoides in the heart of a pregnant woman, leading to a lethal end [6]; thromboembolism of the popliteal artery caused by ascariasis [1] Considering the cycle of ascariasis in Fig. 4. The presence of ascarides and their eggs in the bloodstream explains the effect of ascariasis on the development of cardiovascular pathology.

Detection of ascarids in the cervix [21], which makes it possible to claim anal-vaginal passage.

Non-specific manifestations of ascariasis, which are most commonly encountered by obstetricians and gynecologists include recurrent chronic pelvic inflammatory diseases, especially antibiotic-resistant infections and processes caused by Esherichia colli, Enterococcus faecalis and conditionally pathogenic flora; infertility, unsuccessful attempts at IVF, frozen pregnancies and unauthorized miscarriages, ectopic pregnancy without an infectious gynecological and perinatal cause; acne, manifestations of menstrual syndrome, alopecia, hirsutism, uterine bleeding, recurrent cysts of the right ovary. 


\section{CONCLUSIONS}

More global attention to the diagnosis and treatment of parasitic infections in the examination of women with infertility and reproductive losses is warranted.

The influence of ascariasis as a source of autoinfection of the gastrointestinal tract, allowed us to consider the presence of this invasion a risk factor for the development of chronic inflammatory process of the lower genital tract.

\section{REFERENCES}

1. Ashraf H.Z., Ahangar A.G., Gift F.A. et al. Popliteal artery embolism by Ascaris lumbricoides: a case report. Ulus Trauma Acil Cerrahi Derg. 2009; 15(6):619-20.

2. Asrat T., Rogers N. Acute pancreatitis caused by biliary ascaris in pregnancy. J Perinatol. 1995;15:330-332.

3. Awan K., Ahmad S. Ascaris Lumbricoides - A cause of DVT Leading to Pulmonary Embolism. Journal of Postgraduate Medical Institute (Peshawar - Pakistan). 2011; 14.

4. Bodnya E.I. The problem of parasitic diseases in modern conditions Modern infections. 2009;1:4-11.

5. Bodnya E.I., Sklyarova V.0. Congenital transmission of intestinal nematodes. Current infectology. 2013;1(1):120-122.

6. Caballero D.D., Garcia V.R., Salabarrua F.M. Ascaris lumbricoides en el corazon de una gestante. Presence of Ascaris lumbricoides in the heart of a pregnant woman Rev. cuba. obstet. ginecol. 2011;37(2):243-250.

7. Cerrillo M.P., del Valle M., Navarro A. et al. Ascaris lumbricoides as a cause of incoercible vomiting in a 13-week pregnant woman. Progresos de Obstetricia y Ginecologia 2005;48(9):457-460.

8. Costa-Macedo L.M., Rey L. Ascaris lumbricoides and neonates: records of congenital transmission of intestinal nematodes. Rev Inst Med Trop Sao Paulo. 1990;32(5):351-354.

9. Crompton D.W. Ascaris and ascariasis. Adv Parasitol. 2001;48(1):285-375.

10. Dotters-Katz S., Kuller J., Heine R.P. Parasitic infections in pregnancy. Obstet. Gynecol. Surv. 2011;66(8):515-525.

11. Deveci S., Tanyuksel M., Deveci G., Araz E. Spontaneous missed abortion caused by Ascaris lumbricoides. Cent Eur J Public Health. 2001;9(4):188-189.

12. Efimov G.E., Mavzutov A.R., Kaidanek T.V. et al. Optimization of the laboratory component of the diagnostic subsystem of epidemiological surveillance for ascariasis invasion. Epidemiology and infectious diseases. 2013;5:18-21.

13. El-Moghazy F.M. Impact of Parasitic Infestation on Ovarian Activity in Buffaloes-Heifers with Emphasis on Ascariasis World Journal of Zoology 2011;6(2):196-203.

14. Fiona L.H., Fiona M.M., Craig W.R. Pregnancy and Susceptibility to Parasites. Sex Hormones and Immunity to Infection. 2010;5:227-256.

15. Gimez-Delgado A., Rivera-Cedillo R. Prevalence and risk factors associated with intestinal parasitoses in pregnant women and their relation to infant birth weight. Ginecol Obstet Mex. 2002;70:338-43.

16. Guadalupe I., Miter E., Benitez S.et al. Evidence for utero sensitization to Ascaris lumbricoides in newborns of mothers with ascariasis. The Journal of infectious diseases. 2009.;199:1846-1850.

17. Gupta A., Rathore A.M., Manaktala U. Ascariasis presenting as acute abdomen during pregnancy and puerperium. Southeast Asian J. Trop. Med. Public. Health. 2013;44(2):150-153.

18. Hefny A.F., Saadeldin Y.A., Abu-Zidan F.M. Management algorithm for intestinal obstruction due to ascariasis: a case report and review of the literature. Ulus Travma Acil Cerrahi Derg. 2009;15(3):301-305.
19. Jones J.L., Schulkin J., Maguire J.H. Therapy for common parasitic diseases in pregnancy in the United States: a review and a survey of obstetrician/gynecologists' level of knowledge about these diseases. Obstet Gynecol Surv. 2005;60(6):386-393.

20. Klyaritskaya I.L.,Viltsanyuk I.A., Grigorenko E.I., Chernukha S.N. Modern ideas about the treatment and diagnosis of helminthiasis. Crimean therapeutic journal. 2010;2:144-147.

21. Mali B.N., Hazari K.T., Meherji P.K. Ascaris lumbricoides eggs in vaginal wet smear. Diagn Cytopathol. 2006;34(5):387-8.

22. Malla N.S., Ganguly B.A. In vitro effect of larval stages of Ascaris lumbricoides on human blood clotting. Journal of Helminthology. 1991;65(2):133-140.

23. Markin L.B., Sklyarova V.A. Features of hormonal background in women with primary infertility and parasitic lesions. Experimental and clinical physiology and biochemistry. 2015;3:77-83.

24. Mehta R.S., Guadalupe I., Mitre E. et al. Maternal geohelminth infections are associated with an increased susceptibility to geohelminth infection in children: a case-control study. PLoS Negl Trop Dis. 2012;6(7):753.

25. Nosalska D., Paluszkiewicz J., Kijuk I., Przesmycki K. Severe sepsis after spontaneous abortion in a patient with coexisting ascariasis. Anest Int Ter. 2007;39(1):36-38.

26. Olds G.R. Deworming the world. Trans Am Clin Climatol Assoc. 2013;124:265-74.

27. Paul R.J., Giuseppina A., Fabrizio G. Eosinophilia and Thrombosis in Parasitic Diseases: An Overview Clin Appl Thromb Hemost. 2011;17:33.

28. Rather A.A., Salati S.A.. Non Obstetric Acute Abdomen in Pregnancy - An Experience from Kashmir. 0JHAS. 2013;12:3.

29. Rebrova 0.Yu. Statisticheskiy analiz meditsinskikh dannykh. Primenenie prikladnykh programm Statistica. Moskva, RF: Media Sfera; 2002.512 p. (in Russian).

30. Sanjeevi C.B., Vivekanandan S., Narayanan P.R. Fetal response to maternal ascariasis as evidenced by anti ascaris lumbricoides $\lg M$ antibodies in the cord blood. Acta Paediatr Scand. 1991;80(12):1134-8.

31. Schneider W. Thrombocyte antibodies due to hetero-immunization caused by ascariasis? /Med Monatsschr. 1966; 2(1):47-50.

32. Shah 0.J., Robanni I., Khan F. Management of Biliary Ascariasis in Pregnancy. World Journal of Surgery. 2005;29(10):1294-1298.

33. Shreiner E.V. Helminthoses in the clinical practice of the pediatrician: issues of diagnosis, therapy, prevention. Russian Medical Journal. 2013;14:773-777.

34. Singh D., Vasudeva P., Dalela D., Sankhwar S.N. Ascaris lumbricoides: A stranger in the urinary bladder causing urinary retention. J Postgrad Med. 2010;56:222-3.

35. Sklyarova V.0. Askariasis - is there any influence on infertility? Is it capable of causing postpartum endometritis? Taurian Medico-Biological Bulletin. 2012;15,2(58):247-248.

36. Sklyarova V.A. Features of vaginal microbiocenosis in women with primary infertility and parasitic lesions. Clinical and experimental pathology. 2014;13,4(50):119-125.

37. Sklyarova V. Helminthiasis as impact factor of gynecological disorders. Indian J Sex Transm. Dis. 2010; 31: 58-60.

38. Sklyarova V.A. State of the L-arginine/NO synthase/arginase system in peripheral blood lymphocytes of women with the risk of pregnancy termination. Experimental and clinical physiology and biochemistry. 2013;1:69-73.

39. Sklyarova V.A. Treatment of mixed urogenital infection in women of reproductive age with parasitic lesions. Clinical pharmacy, pharmacotherapy and medical standardization. 2014;24-25:112-115. 
40. Stermer E., Bassan H., Oliven A. et al. Massive thrombosis as a result of triple infestation of the pulmonary arterial circulation by Ascaris, Candida, and Mucor. Human Pathology. 1984;15(10):996.

41. Fedorchenko G.A. Helminthosis in the practice of obstetriciangynecologist. Medical aspects of women's health. 2010;5(6):30-34.

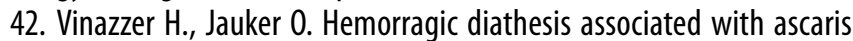
infestation. Wien Med Wochenschr. 1964;20(114):471-473.

43. Yakasai1 I.A., Umar U.A. Review of parasitic infestation in pregnancy. Asian journal of natural \& applied sciences. 2013;2(1):31-38.

44. Zapardiel I., Peiretti M., Godoy-Tundidor S. Concurrent puerperal hysterectomy with Ascaris lumbricoides infestation: coincidence or consequence? American Journal of Obstetrics \& Gynecology. 2010;202(4): e4-e5.

45. Ctnters for diseases control and preventation. Parasites - Ascariasis. www.cdc.gov/parasites/ascariasis [data access 17.08.2020]

46. Human roundworm. www.npblog.com.ua/index.php/zoologiya/ ljudska-askarida.html [data access 17.08.2020]

47. Medical biology. http://subject.com.ua/biology/medical/263.html [data access 17.08.2020]

\section{ORCID and contributionship:}

Valentyna Sklyarova: 0000-0002-2863-545X A, B, D, F

Kateryna Shatylovich: 0000-0002-8465-0355 ${ }^{B, F}$

Pavlo Sklyarov: 0000-0002-1814-2459 ${ }^{E}$

Anzhelika Filipyuk: 0000-0001-6641-0780 ${ }^{\mathrm{C}}$

\section{Conflict of interest:}

The Authors declare no conflict of interest.

\section{CORRESPONDING AUTHOR Valentyna Sklyarova \\ Danylo Halytskyy Lviv State Medical University 69 Pekarska str, 79010 Lviv, Ukraine \\ tel: +380677647766 \\ e-mail: valisklyarova@hotmail.com}

Received: 28.09 .2020

Accepted: 02.08 .2021
A - Work concept and design, B - Data collection and analysis, C - Responsibility for statistical analysis,

$\mathbf{D}$-Writing the article, $\mathbf{E}$-Critical review, $\mathbf{F}$ - Final approval of the article 